TITLE:

\title{
Atypical verbal communication pattern according to others' attention in children with Williams syndrome
}

\section{$\operatorname{AUTHOR}(\mathrm{S})$ :}

Asada, Kosuke; Tomiwa, Kiyotaka; Okada, Masako; Itakura, Shoji

\section{CITATION:}

Asada, Kosuke ...[et al]. Atypical verbal communication pattern according to others' attention in children with Williams syndrome. Research in developmental disabilities 2010, 31(2): 452-457

ISSUE DATE:

2010-03

URL:

http://hdl.handle.net/2433/115104

\section{RIGHT:}

(c) 2010 Elsevier B.V.; この論文は出版社版でありません。引用の際には 出版社版をご確認ご利用ください。; This is not the published version. Please cite only the published version. 
$\underline{\text { Research in Developmental Disabilities } 31 \text { (2010) 452-457 }}$

doi:10.1016/j.ridd.2009.10.010

Running head: ATYPICAL VERBAL COMMUNICATION IN WILLIAMS

SYNDROME

Atypical Verbal Communication Pattern According to Others' Attention in Children with Williams Syndrome

Kosuke Asada ${ }^{1}$, Kiyotaka Tomiwa ${ }^{2,3}$, Masako Okada ${ }^{3}$, Shoji Itakura ${ }^{1}$

1 Department of Psychology, Graduate School of Letters, Kyoto University, Yoshida-honmachi, Sakyo, Kyoto 606-8501, Japan

${ }^{2}$ Genetic Counselling and Clinical Research Unit, Graduate School of Medicine, Kyoto University, Yoshida-konoecho, Sakyo, Kyoto 606-8501, Japan

3 Osaka City General Hospital, 2-13-22, Miyakojima-hondori, Miyakojima, Osaka 534-0021, Japan

Correspondence should be addressed to Kosuke Asada, Department of Psychology, Graduate School of Letters, Kyoto University, Yoshida-honmachi, Sakyo, Kyoto 606-8501, Japan. E-mail: kousuke@ka1.mbox.media.kyoto-u.ac.jp Phone/Fax: 


\begin{abstract}
Children with Williams syndrome (WS) have been reported to often face problems in daily communication and to have deficits in their pragmatic language abilities. To test this hypothesis, we examined whether children with WS could modify their verbal communication according to others' attention in order to share what they did. The children with WS and typically developing (TD) children were asked to accomplish tasks as quickly as possible while the experimenter was attending to or not attending to them during and after their accomplishment. The results showed that although TD children verbalized more when they were not attended to than attended to, children with WS verbalized more when they were attended to than not attended to. The results indicate that children with WS may have deficits in attention-sharing communication, suggesting a part of their pragmatic abilities is impaired.
\end{abstract}

Keywords: Williams syndrome; Pragmatics; Verbal communication 
Atypical Verbal Communication Pattern According to Others' Attention in Children with Williams Syndrome

\section{Introduction}

Williams syndrome (WS) is a rare genetic neurodevelopmental disorder. It is caused by a microdeletion of chromosome 7q11.23 (Ewart, Morris, Atkinson, Jin, Sternes, Spallone, Stock, Leppert, \& Keating, 1993). The phenotype of WS has been characterized by relatively strong language abilities and weak visuospatial cognition (Bellugi, Lichtenberger, Jones, Lai, \& St. George, 2000; Mervis, Morris, Bertrand, \& Robinson, 1999; Udwin, Yule, \& Martin, 1987). However, recent studies showed that language abilities of individuals with WS are not as advanced as previously claimed. For example, their receptive grammatical ability is no better than their overall mental age (see Brock, 2007, for a review).

Furthermore, some clinical research reported that children with WS faced a lot of problems in daily communication. Udwin et al. (1987) asked the parents and/or teachers of children with WS about their children's difficulties. They reported that the problems faced by their children included chattering incessantly at a superficial level and speaking in an old-fashioned manner. Moreover, Laws and Bishop (2004) used communication checklists for parents, and revealed that children with WS showed difficulties especially in the inappropriate initiation of conversation and the use of stereotyped conversation. Philofsky, Fidler, and Hepburn (2007) used the same checklists for parents, and compared the outcome of children with WS with that of children with Autism Spectrum Disorders, who are known to have deficits in social and 
communicative skills. They found that the extent of difficulties in the inappropriate initiation of conversation and the use of context was not different between children with WS and those with Autism Spectrum Disorders. These reports implied that children with WS have deficits in pragmatic language abilities. Pragmatic abilities are broadly defined as the abilities to use language in a social context for the purpose of communication. Specifically, pragmatic abilities include turn-taking, politeness (to speak in a polite manner), communicating according to others' state (communicating while taking account of others' attention, belief, etc.) and so on (Clark, 2004).

While clinical investigations have reported converging evidence in the pragmatic deficits in WS, previous studies using experiments or semi-structured conversations on this topic have presented rather mixed evidence. Several studies demonstrated that individuals with WS performed relatively well in communication tasks. Jones, Bellugi, Lai, Chiles, Reilly, Lincoln, and Adolphs (2000) conducted a semi-structured interview with adolescents and adults with WS. Participants were questioned about their family, activities, and interests, and then received follow-up questions in line with natural conversational flow. They revealed that individuals with WS used expressions — such as descriptions of affective states and emphatic markers - to elaborate their stories more frequently than those with Down syndrome and developmental age-matched typically developing (TD) controls. In the same paper, Jones et al. (2000) investigated narratives of children with WS. Children were asked to tell a story to the experimenter after seeing a wordless picture book. They revealed that children with WS used exclamatory phrases such as sound effects or character speech, 
which seemed to function to renew and maintain audience attention, more frequently than chronological age-matched TD children. Furthermore, Reilly, Losh, Bellugi, and Wulfeck (2004) found the same result in children with WS in a broader age range, as compared with children with specific language impairment.

In contrast, Stojanovik (2006) showed that children with WS had a deficit on another communication task although there are far fewer reports of deficits than of good expressive language skills. In her study, children were shown some photographs representing everyday scenes and were encouraged to talk about their own experiences related to the topic. The adult partner sometimes asked prepared questions when it was felt that the conversation was not progressing. Stojanovik found that children with WS added new information less frequently in their replies although they uttered more words than those with specific language impairment.

These two lines of studies may seem contradictory because they represent both strengths and weaknesses in the pragmatic abilities of individuals with WS. However, the apparently contrasting evidence might shed light on the unique features of their pragmatic abilities. As the previous studies revealed, although individuals with WS demonstrated good performance by using elaborate expressions in describing stories, they had difficulty in making relevant replies in reciprocal conversations. Individuals with WS might have relatively good skills to express their meaning by using elaborate language (e.g. narrative) but might have deficits in the ability to use them according to their listeners' state (e.g. relevant replies). As suggested by pragmatic theories, human communication is typically supposed to be relevant for both the speaker and listener, 
and the speaker is often required to talk while taking account of the situation of the listener (Grice, 1975; Sperber \& Wilson, 1995). The previous clinical investigations might detect such deficits in individuals with WS because daily communication, which includes communication breakdowns, necessity of clarification, etc., often requires them to communicate according to others' state. Individuals with WS might have specific difficulty in communicating according to others' state. This study focused on this aspect of the pragmatic abilities of individuals with WS.

Previous studies reported that TD children can use pragmatic communication skills early in development (Ferrier, Dunham, \& Dunham, 2000; O’Neill, 1996; Shwe \& Markman, 1997). For example, O’Neill (1996) showed that two-year-olds named a toy and its location more frequently when their parent did not know of the location than when she or he did in situations where they sought their parent's help in retrieving the toy. In addition, previous studies reported that most children with WS began to produce language before they began to point in their communicative development, and this developmental pattern was opposite to the pattern shown by other groups of children, such as TD children and children with Down syndrome (Laing, Butterworth, Ansari, Gsödl, Longhi, Panagiotaki, Paterson, \& Karmiloff-Smith, 2002; Mervis \& Bertrand, 1997). Pointing is thought to have several prototypical pragmatic functions, which are found in human conversation (Bates, Camaioni, \& Volterra, 1975; Tomasello, Carpenter, \& Liszkowski, 2007). The relatively late emergence of pointing for individuals with WS supports the view that their difficulty in pragmatic abilities might appear during early verbal communication. 
In the present study, we investigated one of the pragmatic abilities, that is, communicating according to others' state, which was assumed to be impaired in children with WS on the basis of the previous studies. Specifically, we examined whether children with WS in comparison to TD children could modify their communication according to when they were attended to or not attended to in a situation where they needed to share something with the experimenter.

We expected that TD children would think that the experimenter did not know when and how they achieved the tasks when they were not attended to whereas they would think that he knew it to some extent when they were attended to. Therefore, we predicted that TD children would verbalize more when they were not attended to than attended to in order to share what they did with the experimenter. In contrast, children with WS were hypothesized as having difficulty in communicating according to the experimenter's state. Thus, we predicted that, unlike TD children, children with WS would not verbalize more when they were not attended to than attended to. In other words, we predicted that they would not verbalize appropriately according to the experimenter's attention.

2. Method

\subsection{Participants}

Diagnosis of all the children with WS was made by a clinical geneticist and confirmed by the fluorescence in situ hybridization (FISH) test for the deletion of the elastin gene. TD children were recruited using a database of parents who had 
volunteered to participate in studies concerning child development. All the children took the Picture Vocabulary Test (PVT; Ueno, Utsuo, \& Iinaga, 1991) for measuring their vocabulary age.

Fifteen children with WS ( 6 boys and 9 girls) were individually matched on the basis of sex and vocabulary age (within a range of \pm 3 months) with 15 TD children (6 boys and 9 girls). The mean vocabulary age of the WS group was 4;5 (range: $2 ; 2$ to $5 ; 10$ ), and that of the TD group was $4 ; 5$ (range: $2 ; 0$ or below to $5 ; 9)^{1}$. The mean chronological age of the WS group was $10 ; 2$ (range: $6 ; 4$ to $18 ; 4$ ), and that of the TD group was $4 ; 3$ (range: $2 ; 8$ to $5 ; 9$ ).

\subsection{Procedure}

The experiment was carried out in a hospital room for children with WS, and in a laboratory attached to Kyoto University for TD children. We used three toys for eliciting children's communication. The first toy was a fishing toy. In this task, children were required to fish three sea creature toys which had a clip, using a rod with a magnet attached to its end. The second toy was a puzzle. In this task, children were required to complete 2 two-piece and 1 three-piece puzzles depicting the pictures of animals. The third toy was a shape fitting toy. In this task, children were required to fit wooden shapes (circle, triangle, and square) on a base with holes.

The children were given these tasks in a fixed order (1. fishing toy, 2. puzzle, 3.shape fitting toy). They participated in both the Attention and No-Attention conditions in each task. They were asked to accomplish these tasks as quickly as possible. They sat at one side of a table and the experimenter sat at the side next to the children's. In the 
Attention condition, the experimenter attended to the children and the task materials while they accomplished the task. After the accomplishment, the experimenter looked at the children's face (and sometimes looked at the task materials). In the No-Attention condition, the experimenter attended to the opposite direction of the children during and after the accomplishment. The order of conditions was counterbalanced between the children. In all, this experiment comprised six trials (two conditions $\mathrm{X}$ three tasks). The children consecutively participated in the same task twice. However, in order to keep them motivated, we made the second trial different from the first one with regard to some aspects. Specifically, in the second trial, the experimenter asked the children to try to accomplish the tasks faster than they did in the first one, and the contents of the tasks also differed from the first one (e.g. three different sea creatures were used in the fishing toy task). If children seemed to show difficulty in accomplishing the tasks, the experimenter offered advice or helped but these interventions were kept at a minimum.

We recorded the children's behaviors on video and coded them for $10 \mathrm{~s}$ after their accomplishment from the videos. We also measured the time required for the accomplishment from the beginning of the task in order to confirm that the difficulty of the task did not differ between the groups.

\subsection{Coding}

In addition to the time it took to complete the task, we counted the number of the children's behaviors on the basis of the following three categories.

Verbalizations about the accomplishment: We coded utterances such as "I did it!" or "Hey, look!". One utterance was judged on the basis of the contents and pauses in 
reference to the criteria of Shewan (1988).

Looks to the experimenter's face: Behaviors in which the children's head and eyes were oriented to the experimenter's face.

Gesture: Nonverbal behaviors that expressed the accomplishment or drew the experimenter's attention (e.g. reaching or touching the experimenter, showing the accomplished task materials to the experimenter, pointing at the accomplished task materials, and banging the task materials or table which were used in the experiment). The first and second coders independently observed all the data, and counted the children's behaviors. Inter-rater reliability was calculated using Pearson's correlation: verbalizations about the accomplishment $(\mathrm{r}=.930)$, looks to the experimenter's face $(\mathrm{r}=.894)$, and gesture $(\mathrm{r}=.709)$.

\section{Results}

\subsection{Time for the accomplishment}

The mean time for the accomplishment of all the six trials was $27.0 \mathrm{~s}$ (SD:

$16.1)$ in the WS group and $22.8 \mathrm{~s}$ (SD: 16.6) in the TD group. The time for the accomplishment was analyzed using a 2 Group (WS, TD) X 2 Condition (Attention, No-Attention) X 3 Task (Fishing, Puzzle, Shape) three-way mixed-design ANOVA. This analysis revealed a significant main effect of Task $\left(F(2,56)=27.526, p<.001, \eta_{\mathrm{p}}{ }^{2}\right.$ $=.496)$. We did not find any other significant main effects or interactions. Specifically, there was no main effect of $\operatorname{Group}\left(F(1,28)=.483, p=.493, \eta_{\mathrm{p}}{ }^{2}=.017\right)$, which indicates that the difficulty of the tasks did not statistically differ between the groups. 


\subsection{Verbalizations about the accomplishment}

Figure 1 shows the mean number of verbalizations about the accomplishment in the Attention and No-Attention conditions. In order to examine when and how much the children verbally expressed their accomplishment, the verbalizations about their accomplishment were analyzed using a 2 Group (WS, TD) X 2 Condition (Attention, No-Attention) X 3 Task (Fishing, Puzzle, Shape) three-way mixed-design ANOVA. This analysis revealed a significant Group X Condition interaction $(F(1,28)=6.914, p=.014$, $\left.\eta_{\mathrm{p}}{ }^{2}=.198\right)$. There were no other significant main effects or interactions. Follow-up one-way ANOVAs (the Task factor was collapsed by averaging the verbalizations about the accomplishment across the three tasks) revealed that only the TD children verbalized about their accomplishment more in the No-Attention condition than in the Attention condition $\left(F(1,14)=5.304, p=.037, \eta_{\mathrm{p}}{ }^{2}=.275\right)$. Unlike the TD children, the children with WS did not verbalize significantly differently according to the Condition $\left(F(1,14)=2.687, p=.123, \eta_{\mathrm{p}}{ }^{2}=.161\right)$. Rather, they verbalized more in the Attention condition than in the No-Attention condition although this difference did not reach significance.

$$
\text { [place Figure } 1 \text { about here] }
$$

\subsection{Looks to the experimenter's face}

The mean number of looks to the experimenter's face in the WS group was 1.64 (SD: 0.50) in the Attention condition, and 1.33 (SD: 0.70) in the No-Attention condition. The mean number of looks to the experimenter's face in the TD group was 1.88 (SD: 0.65) in the Attention condition, and 1.88 (SD: 0.94) in the No-Attention 
condition. $^{2}$ The looks to the experimenter's face were analyzed using a 2 Group (WS, TD) X 2 Condition (Attention, No-Attention) X 3 Task (Fishing, Puzzle, Shape) three-way mixed-design ANOVA. This analysis revealed a significant main effect of Task $\left(F(2,52)=5.487, p=.007, \eta_{\mathrm{p}}{ }^{2}=.174\right)$. However, there were no other significant main effects or interactions.

\subsection{Gesture}

The mean number of gestures in the WS group was 0.43 (SD: 0.40) in the Attention condition, and 0.24 (SD: 0.42 ) in the No-Attention condition. The mean number of gestures in the TD group was 0.50 (SD: 0.45) in the Attention condition, and 0.45 (SD: 0.48 ) in the No-Attention condition. The gestures were analyzed using a 2 Group (WS, TD) X 2 Condition (Attention, No-Attention) X 3 Task (Fishing, Puzzle, Shape) three-way mixed-design ANOVA. There were no significant main effects or interactions.

\section{Discussion}

This study examined whether children with WS could modify their communication according to others' attention. The results showed that although TD children verbalized more when they were not attended to than when they were attended to, children with WS showed the opposite pattern, verbalizing more when they were attended to than not attended to. Other communicative behaviors, namely gestures, were rare and did not distinguish between the groups. The low production of gestures makes sense given that children this age tend to communicate mainly by verbalizations. In 
addition, the children might have avoided using gestures because it was difficult for the experimenter to notice the children's gestures, especially in the No-Attention condition.

The TD children verbalized more when they were not attended to than when they were attended to in order to draw the experimenter's attention and share what they did with him. The different verbal communication pattern shown by children with WS was not efficient for sharing what they did with the experimenter. It violated the pragmatic rule, that is, to speak the appropriate amount according to others' state, because they did not increase their verbalizations in the No-Attention condition and did not decrease their verbalizations in the Attention condition. We propose the following three factors to account for the atypical verbal communication of children with WS.

The first factor is failure to acquire a communicative function. When children are not attended to, they are more frequently required to draw the experimenter's attention than when they are attended to. To communicate in such situations, children must be able to engage the declarative function, the ability to direct or share attention to something (e.g. Bates et al., 1975; Liszkowski, Carpenter, Henning, Striano, \& Tomasello, 2004; Tomasello et al., 2007). Impairment of this function has been found in children with Autism (e.g. Baron-Cohen, 1989), and is presumed to be critical for normal social communication development. A previous study suggested that the declarative function of children with WS is deficient in non-verbal communication. Laing et al. (2002) investigated the production of pointing in toddlers with WS by presenting them with attractive moving dolls, and found that toddlers with WS produced fewer declarative points than mental age-matched TD infants. 
The second factor is impairment in the ability to understand the meaning of others' attentional state. In the present study, children were required to infer the experimenter's knowledge state on the basis of the presence or absence of his attention and to subsequently verbalize according to his attention. Such inference is thought to be available by acquiring the seeing-leads-to-knowing principle (Pratt \& Bryant, 1990). Although, to the best of our knowledge, there is no direct evidence examining this social cognitive skill of children with WS, there are several studies suggesting that they have deficits in other, related social cognitive skills. Specifically, children with WS have difficulty with false belief understanding (Porter, Coltheart, \& Langdon, 2008;

Tager-Flusberg \& Sullivan, 2000). For example, Tager-Flusberg and Sullivan (2000) revealed that the performance on false belief tasks for children with WS was worse than that for children with other forms of mental retardation. Thus, inappropriate verbalizations for children with WS may stem from a difficulty in understanding the meaning of others' attentional state.

The third potential factor is a distinct tendency to socialize found in individuals with WS. Jones et al. (2000) revealed that individuals with WS had higher motivation to interact with others than TD individuals. They also reported that individuals with WS were more approachable and talked more to strangers than those with Autism or Down syndrome. Furthermore, individuals with WS exhibit strong preferences for social stimuli, such as human eyes and faces (Mervis, Morris, Klein-Tasman, Bertrand, Kwitny, Appelbaum, \& Rice, 2003; Riby \& Hancock, 2008). In this study, the children could see the experimenter's face in the Attention condition, but they may have found it difficult 
to do so in the No-Attention condition. For children with WS, in the Attention condition, looking at the experimenter's eyes or face may have triggered the motivation to interact with the other and consequently increase their verbalizations. On the other hand, in the No-Attention condition, few exposures to social stimuli may have led to indifference toward communication and a consequent decrease in their verbalizations.

Although this study did not reveal which factors most constitute the atypical communication of individuals with WS, we assume that all three factors might together, but at different levels, influence it. Specifically, the impaired declarative function and the difficulty with social cognitive skills might underlie the pragmatic abilities themselves, and the distinct tendency to socialize might affect the functioning of the pragmatic abilities. Further research is required to investigate these deficits and the relation between the factors responsible for pragmatic deficits of individuals with WS.

In conclusion, this study suggests that a part of the pragmatic abilities, that is, communicating according to others' attention, is impaired in children with WS. Individuals with WS have often been portrayed as having good social and communicative skills (e.g. Reilly, Klima, \& Bellugi, 1990). However, this perspective focuses on the relatively unimpaired aspects of their pragmatic abilities, such as good expressive language skills (i.e. to express their meaning with elaborate language), as evidenced by their narrative abilities. Their good expressive language skills might not mean that their overall pragmatic skills are good. Indeed, several impaired skills, such as communicating according to others' attention, probably exist behind the appearance of relatively good skills. Both these abilities_-expressive language skills and 
communicating according to others' state — are important components for successful communication. However, these findings for individuals with WS imply that the underpinnings of these skills might be different. Further studies on individuals with WS would help to clarify the structure of human pragmatic abilities.

\section{Acknowledgments}

The research reported in this paper was supported by JSPS (Japan Society for the Promotion of Science) Research Fellowships for Young Scientists to K.A. and by a grant from JSPS (20330150) to S.I.. We thank Tara Callaghan, Yasuhiro Kanakogi, Aya Kutsuki, Yusuke Moriguchi, Yuko Okumura, and Mako Okanda for their insightful comments on the earlier versions of this paper. We are grateful to Hayashi Ayabe for his help in data collection and Masashi Sugimoto for his help in data coding. We are also grateful to all the children and parents for their participation in this study. 


\section{References}

Baron-Cohen, S. (1989). Perceptual role taking and protodeclarative pointing in autism. British Journal of Developmental Psychology, 7, 113-127.

Bates, E., Camaioni, L., \& Volterra, V. (1975). The acquisition of performatives prior to speech. Merrill-Palmer Quarterly, 21, 205-226.

Bellugi, U., Lichtenberger, L., Jones, W., Lai, Z., \& St. George, M. (2000). The neurocognitive profile of Williams syndrome: A complex pattern of strengths and weaknesses. Journal of Cognitive Neuroscience, 12(Supplement), 7-29.

Brock, J. (2007). Language abilities in Williams syndrome: A critical review. Development and Psychopathology, 19, 97-127.

Clark, E. V. (2004) Pragmatics and language acquisition. In L. R. Horn \& G. Ward (Eds.), Handbook of pragmatics (pp.562-577). Oxford: Blackwell.

Ewart, A. K., Morris, C. A., Atkinson, D., Jin, W., Sternes, K., Spallone, P., Stock, A. D., Leppert, M., \& Keating, M. T. (1993). Hemizygosity at the elastin locus in a developmental disorder, Williams syndrome. Nature Genetics, 5, 11-16.

Ferrier, S., Dunham, P., \& Dunham, F. (2000). The confused robot: Two-year-olds' responses to breakdowns in conversation. Social Development, 9, 337-347.

Grice, H. P. (1975). Logic and conversation. In P. Cole \& J. L. Morgan (Eds.), Syntax and semantics. Speech acts (Vol. 3, pp. 41-58). New York: Academic Press.

Jones, W., Bellugi, U., Lai, Z., Chiles, M., Reilly, J., Lincoln, A., \& Adolphs, R. (2000). Hypersociability in Williams syndrome. Journal of Cognitive Neuroscience, 12(Supplement), 30-46. 
Laing, E., Butterworth, G., Ansari, D., Gsödl, M., Longhi, E., Panagiotaki, G., Paterson, S., \& Karmiloff-Smith, A. (2002). Atypical development of language and social communication in toddlers with Williams syndrome. Developmental Science, 5, $233-246$.

Laws, G., \& Bishop, D. V. M. (2004). Pragmatic language impairment and social deficits in Williams syndrome: a comparison with Down's syndrome and specific language impairment. International Journal of Language and Communication Disorders, 39, 45-64.

Liszkowski, U., Carpenter, M., Henning, A., Striano, T., \& Tomasello, M. (2004). Twelve-month-olds point to share attention and interest. Developmental Science, 7, 297-307.

Mervis, C. B., \& Bertrand, J. (1997). Developmental relations between cognition and language: Evidence from Williams syndrome. In L. B. Adamson \& M. A. Romski (Eds.), Communication and language acquisition: Discoveries from atypical development (pp.75-106). Baltimore, MD: Paul H. Brookes.

Mervis, C. B., Morris, C. A., Bertrand, J., \& Robinson, B. F. (1999). Williams syndrome: findings from an integrated program of research. In $\mathrm{H}$. Tager-Flusberg (Ed.), Neurodevelopmental disorders (pp. 65-110). Cambridge, MA: MIT Press.

Mervis, C. B., Morris, C. A., Klein-Tasman, B. P., Bertrand, J., Kwitny, S., Appelbaum, L. G., \& Rice, C. E. (2003). Attentional characteristics of infants and toddlers with Williams syndrome during triadic interactions. Developmental 
Neuropsychology, 23, 243-268.

O'Neill, D. K. (1996). Two-year-old children's sensitivity to a parent's knowledge state when making requests. Child Development, 67, 659-677.

Philofsky, A., Fidler, D.J., \& Hepburn, S. (2007). Pragmatic language profiles of school-age children with autism spectrum disorders and Williams syndrome. American Journal of Speech-Language Pathology, 16, 368-380.

Porter, M.A., Coltheart, M., \& Langdon, R. (2008). Theory of mind in Williams syndrome assessed using a nonverbal task. Journal of Autism and Developmental Disorders, 38, 806-814.

Pratt, C., \& Bryant, P. (1990). Young children understand that looking leads to knowing (so long as they are looking into a single barrel). Child Development, 61, 973-982.

Reilly, J., Klima, E. S., \& Bellugi, U. (1990). Once more with feeling: Affect and language in atypical populations. Development and Psychopathology, 2, $367-391$.

Reilly, J., Losh, M., Bellugi, U., \& Wulfeck, B. (2004). "Frog, where are you?” Narratives in children with specific language impairment, early focal brain injury, and Williams syndrome. Brain and Language, 88, 229-247.

Riby, D. M., \& Hancock, P. J. B. (2008). Viewing it differently: Social scene perception in Williams syndrome and Autism. Neuropsychologia, 46, 2855-2860.

Shewan, C. M. (1988). The Shewan Spontaneous Language Analysis (SSLA) system for aphasic adults: description, reliability, and validity. Journal of Communication 
Disorders, 21, 103-138.

Shwe, H. I., \& Markman, E. M. (1997). Young children's appreciation of the mental impact of their communicative signals. Developmental Psychology, 33, $630-636$.

Sperber, D., \& Wilson, D. (1995). Relevance: Communication and cognition (2nd ed.). Oxford: Blackwell.

Stojanovik, V. (2006). Social interaction deficits and conversational inadequacy in Williams syndrome. Journal of Neurolinguistics, 19, 157-173.

Tager-Flusberg, H., \& Sullivan, K. (2000). A componential view of theory of mind: evidence from Williams syndrome. Cognition, 76, 59-89.

Tomasello, M., Carpenter, M., \& Liszkowski, U. (2007). A new look at infant pointing. Child Development, 78, 705-722.

Udwin, O., Yule, W., \& Martin, N. (1987). Cognitive abilities and behavioural characteristics of children with idiopathic infantile hypercalcaemia. Journal of Child Psychology and Psychiatry, 28, 297-309.

Ueno, K., Utsuo, T., \& Iinaga, K. (1991). Kaiga goi hattatsu kensa [Picture vocabulary test]. Tokyo: Nihon Bunka Kagakusha. 


\section{Footnotes}

${ }^{1}$ The vocabulary age ' $2 ; 0$ or below' (which was due to the performance of one TD child) was replaced by ' $2 ; 0$ ' when the group matching and mean calculation were done.

${ }^{2}$ Fourteen children with WS and 14 TD children were analyzed for the looks to the experimenter's face and gesture. One child with WS had to be excluded from these analyses because she moved out of the range of the camera angle. Therefore, one TD child, who was matched with her in sex and vocabulary age, also had to be excluded. 


\section{Atypical Verbal Communication 22}

\section{Figure Caption}

Figure 1. Mean number of verbalizations about the accomplishment in the Attention and No-Attention conditions. The error bars indicate standard errors. 
Figure 1.

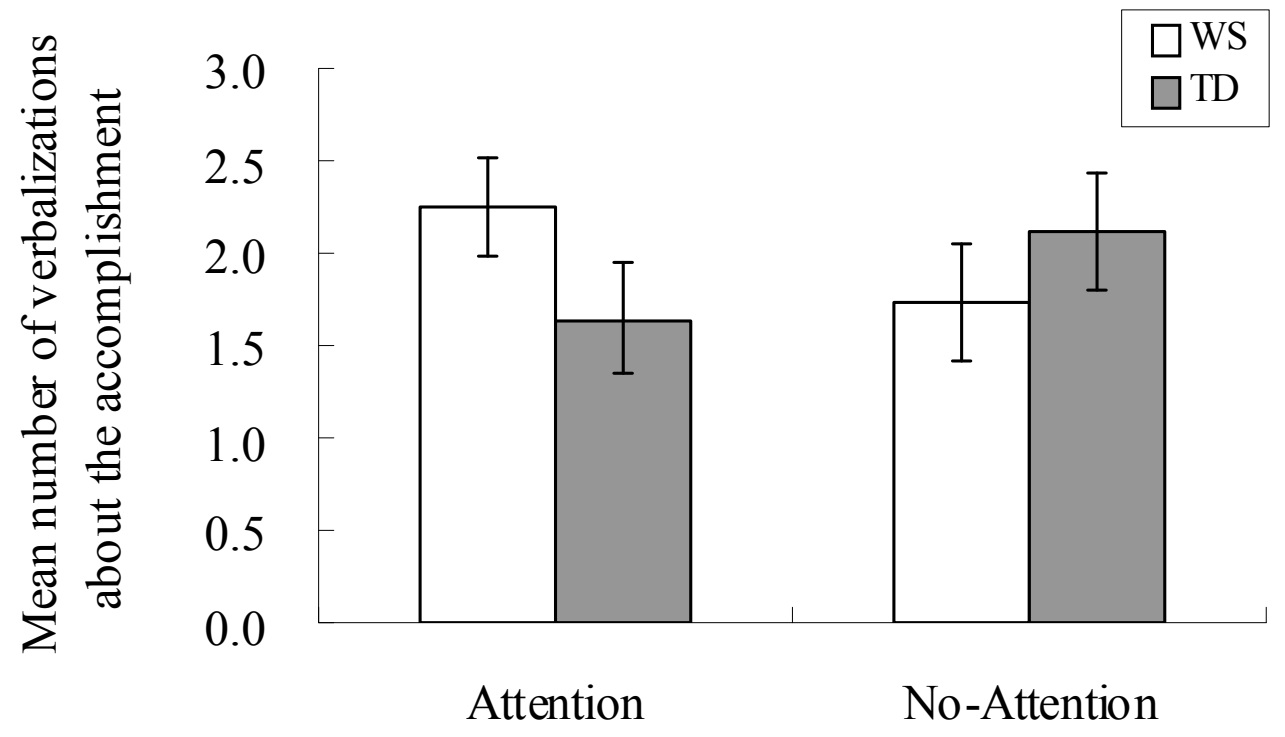

